\title{
Acute kidney injury in acute respiratory distress syndrome: why ventilator settings matter
}

\author{
Rishik Vashisht, Abhijit Duggal \\ Respiratory Institute, Cleveland Clinic Foundation, Cleveland, OH, USA \\ Correspondence to: Abhijit Duggal, MD, MPH, MSc, FACP. Department of Critical Care Medicine, Respiratory Institute, 9500 Euclid Avenue, \\ Cleveland, OH 44195, USA. Email: duggala2@ccf.org. \\ Provenance and Peer Review: This is an invited article commissioned by the editorial office, Annals of Translational Medicine. The article did not undergo \\ external peer review. \\ Comment on: Leite TT, Gomes CAM, Valdivia JMC, et al. Respiratory parameters and acute kidney injury in acute respiratory distress syndrome: a \\ causal inference study. Ann Transl Med 2019;7:742.
}

Submitted Mar 03, 2020. Accepted for publication Apr 16, 2020.

doi: $10.21037 /$ atm-20-2163

View this article at: http://dx.doi.org/10.21037/atm-20-2163

Acute respiratory distress syndrome (ARDS) is an inflammatory syndrome and is associated with a mortality of around $40 \%$ (1). This mortality is largely attributed to the multisystem organ failure (MSOF) that ensues after the development of ARDS. Sub-optimal ventilator strategies propagate alveolar capillary membrane damage potentiating an inflammatory response which in turn can worsen the MSOF (2). Patients with higher levels of circulating proinflammatory cytokines have been found to have higher mortality (3). Sub-optimal conventional ventilation can worsen MSOF by day 3, with the kidneys being the most affected organs (2). The prevalence of acute kidney injury (AKI) in critically ill patients is estimated to be around $30 \%$ (4) and is associated with poor outcomes (5). This percentage further increases to around $45 \%$ in patients with ARDS (6). Patients with ARDS who develop AKI have a higher hospital mortality rate than those without AKI (6). Over the years, there has been increasing body of evidence linking mechanical ventilation and ARDS as independent risk factors for developing AKI in addition to well known risk factors like age, diabetes, cardiac and hepatic dysfunction $(6,7)$. Various mechanisms postulated for development of AKI include hemodynamic, neurohormonal and metabolic derangements (8-10). Increased intrathoracic pressure due to ventilator leads to decreased cardiac output, subsequently leading to decreased renal perfusion. In addition, low oxygen saturation and hypercapnia targets used in ARDS management leads to increases in diuresis and in renal resistive indices (11). These ultimately lead to decrease in glomerular filtration rate (GFR) and subsequently AKI. The delay in ARDS and subsequent AKI is around 2 days. This is detected by the rise in routinely used markers of kidney injury like BUN, creatinine and decrease in urine output. However, these biomarkers are seen after the injury has already taken place. Several biomarkers have been evaluated to detect the renal stress before the onset of functional change (12) and may help identify at risk kidneys. There is paucity of data regarding the causality of AKI with independent ventilator associated parameters like PEEP, tidal volume, driving pressure and respiratory system compliance. In ARMA trial, patients who had a low tidal volume and limited plateau pressure had a greater number of days without renal failure (13). Development of AKI has been independently associated with age, a history of diabetes mellitus and arterial $\mathrm{pH}$ on day 1 of ARDS and no association between development of AKI and low tidal volume ventilation, limited plateau pressure, and PEEP level (14).

In the current era of targeting mechanical ventilation to decrease the deleterious effects of VILI, it becomes imperative to study the effects of individual components of ventilator mechanics on other organs. In this issue of Annals of Translational Medicine, Leite and colleagues present the results of a large retrospective study assessing the ventilator related parameters associated with subsequent development of AKI in mechanically ventilated patients. Using a large 
database, the authors concluded that respiratory system compliance and PEEP are the only respiratory related variables that had a direct causation with the development of severe AKI. On further using mediation analysis only PEEP mediated a small effect on respiratory system compliance (Csr) on severe AKI. Compliance largely is an intrinsic property of the injured lung and poor Crs represents higher disease severity. This in turn would lead to higher chances of MOSF including AKI. The authors also conclude that PEEP is associated with AKI, however, hemodynamic changes from PEEP did not mediate the effect. We know from the animal and human studies that PEEP dampens the inflammatory cascade by preventing atelectrauma and biotrauma $(15,16)$. The effects of PEEP could however be explained by using the concept of mechanical power. Gattinoni and colleagues proposed a concept of using mechanical power equation to estimate the contribution of the different ventilator-related causes of lung injury and of their variations (17). This equation uses respiratory rate, tidal volume, PEEP, respiratory system elastance, inspiratory-to-expiratory time ratio and airway resistance to calculate the mechanical power transferred to lungs by the ventilator. PEEP may decrease lung inhomogeneity and decrease atelectrauma, however it can also increase the ventilator pressure load. When it causes a greater rise in pressure load it may lead to VILI, which in turn can lead to AKI. The authors also mention the crosstalk theory between organs where worsening lung function can lead to worsening AKI and worsening AKI could lead to worsening lung function. Clemens et al. explored this bidirectional pathway in their study and found strong evidence of reciprocal risk of AKI and ARDS in critically ill burn patients (18).

Despite evolving knowledge of various pathophysiological mechanisms that contribute to AKI in mechanically ventilated patients, little data has emerged in regards to the contribution of individual ventilator parameters like PEEP, tidal volumes, driving pressure and plateau pressures. Long term effects of permissive hypercapnia and hypoxemia on kidneys are still not understood properly. An interesting concept would be to extrapolate the mechanical power equation and see if it can predict the development of AKI. As our understanding about the crosstalk between organs evolve, there is little doubt about the reciprocal relationship between kidneys and lungs. Treating one organ at the expense of other organ might be short sighted. Therefore, larger studies are needed to look into novel concepts such as "pneumo-renal syndrome", identify at risk kidney and mitigate risk factors for prevention of AKI. Based on the current available evidence the appropriate way to prevent AKI in ARDS patients is by using lung protective ventilation, balanced resuscitation, preventing fluid overload and avoidance of nephrotoxic medications. Because of our limited understanding, our ability to prevent and treat ARDS associated AKI is also limited. Therefore, future clinical trials focusing on the ARDS-AKI relationship, especially the effects of individual ventilator parameters are warranted.

\section{Acknowledgments}

Funding: None.

\section{Footnote}

Conflicts of Interest: Both authors have completed the ICMJE uniform disclosure form (available at http://dx.doi. org/10.21037/atm-20-2163). The authors have no conflicts of interest to declare.

Ethical Statement: The authors are accountable for all aspects of the work in ensuring that questions related to the accuracy or integrity of any part of the work are appropriately investigated and resolved.

Open Access Statement: This is an Open Access article distributed in accordance with the Creative Commons Attribution-NonCommercial-NoDerivs 4.0 International License (CC BY-NC-ND 4.0), which permits the noncommercial replication and distribution of the article with the strict proviso that no changes or edits are made and the original work is properly cited (including links to both the formal publication through the relevant DOI and the license). See: https://creativecommons.org/licenses/by-nc-nd/4.0/.

\section{References}

1. Bellani G, Laffey JG, Pham T, et al. Epidemiology, Patterns of Care, and Mortality for Patients With Acute Respiratory Distress Syndrome in Intensive Care Units in 50 Countries. JAMA 2016;315:788-800.

2. Ranieri VM, Giunta F, Suter PM, et al. Mechanical ventilation as a mediator of multisystem organ failure in acute respiratory distress syndrome. JAMA 2000;284:43-4.

3. Bos LD, Schouten LR, van Vught LA, et al. Identification and validation of distinct biological phenotypes in patients 
with acute respiratory distress syndrome by cluster analysis. Thorax 2017;72:876-83.

4. Srisawat N, Sileanu FE, Murugan R, et al. Variation in risk and mortality of acute kidney injury in critically ill patients: a multicenter study. Am J Nephrol 2015;41:81-8.

5. Hoste EAJ, Kellum JA, Selby NM, et al. Global epidemiology and outcomes of acute kidney injury. Nat Rev Nephrol 2018;14:607-25.

6. Darmon M, Clec'h C, Adrie C, et al. Acute respiratory distress syndrome and risk of AKI among critically ill patients. Clin J Am Soc Nephrol 2014;9:1347-53.

7. van den Akker JP, Egal M, Groeneveld AB. Invasive mechanical ventilation as a risk factor for acute kidney injury in the critically ill: a systematic review and metaanalysis. Crit Care 2013;17:R98.

8. Hepokoski M, Englert JA, Baron RM, et al. Ventilatorinduced lung injury increases expression of endothelial inflammatory mediators in the kidney. Am J Physiol Renal Physiol 2017;312:F654-60.

9. Husain-Syed F, Slutsky AS, Ronco C. Lung-Kidney CrossTalk in the Critically Ill Patient. Am J Respir Crit Care Med 2016;194:402-14.

10. Sharkey RA, Mulloy EM, O'Neill SJ. The acute effects of oxygen and carbon dioxide on renal vascular resistance in patients with an acute exacerbation of COPD. Chest 1999;115:1588-92.

11. Darmon M, Schortgen F, Leon R, et al. Impact of mild hypoxemia on renal function and renal resistive index

Cite this article as: Vashisht B, Duggal A. Acute kidney injury in acute respiratory distress syndrome: why ventilator settings matter. Ann Transl Med 2020;8(9):573. doi: 10.21037/atm-202163 during mechanical ventilation. Intensive Care Med 2009;35:1031-8.

12. Bellomo R, Kellum JA, Ronco C, et al. Acute kidney injury in sepsis. Intensive Care Med 2017;43:816-28.

13. Acute Respiratory Distress Syndrome Network, Brower RG, Matthay MA, et al. Ventilation with lower tidal volumes as compared with traditional tidal volumes for acute lung injury and the acute respiratory distress syndrome. N Engl J Med 2000;342:1301-8.

14. Panitchote A, Mehkri O, Hastings A, et al. Factors associated with acute kidney injury in acute respiratory distress syndrome. Ann Intensive Care 2019;9:74.

15. Tremblay L, Valenza F, Ribeiro SP, Li J, Slutsky AS. Injurious ventilatory strategies increase cytokines and c-fos m-RNA expression in an isolated rat lung model. J Clin Invest 1997;99:944-52.

16. Ranieri VM, Suter PM, Tortorella C, et al. Effect of mechanical ventilation on inflammatory mediators in patients with acute respiratory distress syndrome: a randomized controlled trial. JAMA 1999;282:54-61.

17. Gattinoni L, Tonetti T, Cressoni M, et al. Ventilatorrelated causes of lung injury: the mechanical power. Intensive Care Med 2016;42:1567-75.

18. Clemens MS, Stewart IJ, Sosnov JA, et al. Reciprocal Risk of Acute Kidney Injury and Acute Respiratory Distress Syndrome in Critically Ill Burn Patients. Crit Care Med 2016;44:e915-22. 